\title{
A atuação feminina nos Conselhos da Mulher: um estudo dos Conselhos de Pelotas e de Santa Cruz do Sul/RS
}

The role of women in the Women's

Councils: a study of the Councils of Pelotas and Santa Cruz do Sul/RS

\author{
Rosangela Schulz \\ Dieni Oliveira Rodrigues \\ Ana Cristina L. Mendes
}

\section{Resumo}

$\mathrm{O}$ artigo tem como proposta refletir sobre a atuação feminina em Conselhos Municipais da Mulher. A primeira parte apresenta uma concisa revisão da literatura que discute a legitimidade da representação dos atores presentes nos fóruns de deliberação de políticas públicas no Brasil; a segunda parte inicia com breve apresentação da pesquisa que investigou os Conselhos da Mulher de dois municípios do estado do Rio Grande do Sul, seguida dos dados resultantes do questionário aplicado às conselheiras; por fim, algumas considerações são apresentadas visando configurar o perfil das conselheiras e de pensar os dados à luz da discussão sobre legitimidade da representação.

\section{Palavras-chave}

Direitos da Mulher; Representação; Conselhos Municipais.

\begin{abstract}
The article aims to examine women's role in Women's Municipal Councils. The first part presents a review of the literature that discusses the legitimacy of representation of actors present in forums of public policy deliberations in Brazil. The second part analyzes the research on the Women's Councils of the two municipalities of Rio Grande do Sul (Pelotas e Santa Cruz do Sul). Based on this research we analyze the data from the questionnaire administered to the counselors and finally, some considerations are postulated with the objective of presenting the profile of councilors relating the results of empirical research with the discussion about the legitimacy of representation.
\end{abstract} Keywords

Women's Rights; Representation; Municipal Councils. 


\section{Introdução ${ }^{1}$}

A eleição de uma mulher para a Presidência da República do país tem estimulado debates e investigações sobre a participação feminina na política. Porém, grande parte das pesquisas se limita a buscar explicações para a restrita presença das mulheres como candidatas ou como representantes eleitas para o Poder Legislativo, trabalhando com hipóteses que vão desde a problemática cultural focada na estrutura de dominação, passando por discussões sobre o formato do sistema político partidário e eleitoral, bem como criticando a legislação vigente, inclusive a lei de cotas implantada no país ainda na década de $1990^{2}$. As mulheres estão sub-representadas na política partidária e eleitoral, porém elas marcam presença como atores sociais relevantes nos fóruns de discussão e deliberação de políticas públicas. Esta constatação gerou questionamentos que dão sentido a este artigo: Há especificidades no modelo de conselhos que projetam inclusão feminina? Quem são as mulheres que atuam nestes fóruns? O perfil das conselheiras difere das mulheres que disputam cargos no campo político partidário e eleitoral?

Acreditamos que algumas características dos Conselhos atuem como facilitadores à inclusão feminina, principalmente: o formato de seleção e o trabalho voluntário (não remunerado), fatores que apontam para a necessidade de discutir a legitimidade da representação nestes fóruns. Em relação ao perfil das mulheres, cremos não haver grande distinção entre conselheiras e parlamentares (para ficar no campo do legislativo), o que denuncia maiores custos ou obstáculos à entrada feminina no campo político partidário e eleitoral.

Para responder as questões, ou seja, testar as hipóteses, o artigo apresenta dados da pesquisa que investigou os Conselhos dos Direitos da Mulher de dois municípios gaúchos: Pelotas e Santa Cruz do Sul. Os dados serão trabalhados à luz do debate sobre a legitimidade da representação nos fóruns, focando na atuação das mulheres. Apesar dos dados se limitarem a dois casos, cuja temática é "feminina", impedindo grandes generalizações, é possível supor que muitas das informações são comuns a grande parte dos conselhos que tratam dos direitos das mulheres espalhados pelo país. Além disso, permitem algumas reflexões sobre o formato da atuação feminina nestes novos espaços decisórios.

O artigo está estruturado da seguinte forma: a primeira parte apresenta uma concisa revisão da literatura, que discute a legitimidade da representação dos atores presentes nos fóruns de deliberação de políticas públicas, centrando o interesse na presença feminina; a segunda parte inicia com breve descrição da pesquisa que investigou os Conselhos da Mulher dos dois municípios, seguida dos

\footnotetext{
${ }^{1}$ Este artigo é resultado da pesquisa Conselhos dos Direitos da Mulher: potencialidades e limites de representação de demandas femininas por redistribuição e por reconhecimento, financiada pelo CNPq.

${ }^{2}$ Referências importantes desta discussão são os estudos de Araújo (2001, 2009), Miguel (2000), Miguel e Queiroz (2006), Avelar (2001), Grossi e Miguel (2001) e Pinto (2010).
} 
dados resultantes do questionário aplicado às conselheiras; por fim, algumas considerações com intento de apresentar o perfil das conselheiras e de pensar tais dados à luz da discussão sobre a legitimidade da representação.

\section{A atuação das mulheres nos Conselhos: novo formato de representação?}

De modo diverso do campo político partidário e eleitoral, onde a presença de mulheres é ainda limitada, os Conselhos têm mostrado um quadro mais equilibrado em termos de distribuição de vagas de representação por sexo, embora ainda ocorra uma concentração maior de mulheres em conselhos ligados a temas, papéis ou profissões considerados "femininos".

Os conselheiros, assim como os prefeitos e vereadores - para ficar na esfera municipal -, são representantes que, embora com funções distintas, têm de definir políticas públicas municipais. Porém, há significativas diferenças entre os conselhos e os poderes executivos ou legislativos em relação à forma de seleção e ao modelo de representação. A seleção de representantes para compor os executivos e legislativos ocorre via sufrágio universal, através de eleições diretas onde os candidatos estão, necessariamente, vinculados a partidos políticos; a seleção para compor os conselhos não é tão clara, pois os conselheiros ou as conselheiras, geralmente, são indicados pelo poder público ou por entidades da sociedade civil.

Céli Pinto (2004), ao tratar da significativa atuação das ONGs na recente democracia brasileira, constatou a problemática da legitimidade da seleção, salientando que o representante do congresso, bem ou mal, representa alguns milhares de votos que o elegeu, o que não ocorre com os conselheiros. Discussões em torno da representação nos conselhos mostram que a concepção de representante apenas respondendo aos anseios do representado, como pensado por Hanna Pitkin (1976), não faz sentido nestes espaços, pois tais experiências proporcionam formas de representação mais dinâmicas e interativas, com outros formatos de legitimidade ${ }^{3}$.

Porém, as críticas e os questionamentos parecem não afetarem o modelo, ao menos em termos de crescimento numérico, pois os conselhos continuam a proliferar no país ${ }^{4}$. Tais conselhos são muito diversos, entretanto, é possível verificar algumas semelhanças: são criados por lei, possuem certa autonomia sobre normas, planos e orçamentos em suas áreas de atuação, onde "os membros devem "representar" grupos do setor privado, sindicatos de trabalhadores, órgãos estatais e associações civis, com respaldo social amplo e uma missão que corresponda às finalidades do conselho" (ABERS e KECK, 2008, p. 100).

\footnotetext{
${ }^{3}$ Ver: Tótora e Chaia (2004) Lavalle, Houtzager e Castello (2006); Avritzer, (2007); Lüchmann (2007); Abers e Keck (2008).

${ }^{4}$ Abers e Keck (2008) apresentam uma estimativa de mais de 39.000 conselhos de políticas sociais.
} 
Diferente de Silvana Tótora e Vera Chaia (2004), que defendem os conselhos como uma nova ordem política que combina participação direta da sociedade civil com formas tradicionais de representação política, Rebecca Abers e Margaret Keck (2008) definem a participação nestes espaços como sendo indireta, pois aqueles que são chamados de conselheiros, no caso da sociedade civil, são indivíduos escolhidos por outras organizações. Já os representantes do governo são funcionários públicos ou cargos comissionados indicados pelos órgãos estatais em que trabalham e devem representar seus interesses no conselho. Nos dois casos trata-se de representação, porém a legitimidade não se dá via sufrágio eleitoral.

Para Leonardo Avritzer (2007) a representação da sociedade civil, que tem ocorrido de forma intensa nos conselhos municipais, é uma "representação por afinidade". E acontece a partir da especialização temática e da experiência, pois são atores da sociedade civil que por muito tempo tem lidado com problemas na área das políticas sociais e, que por conta destas experiências, tendem a assumir a função de representantes da sociedade civil.

Segundo o autor, a forma de representação eleitoral possui a autorização através do voto e é legitimada pelo próprio processo eleitoral, sendo que o sentido da representação é justamente fazer a representação de pessoas. A representação do tipo advocacia, exercida, por exemplo, pelos organismos internacionais de defesa do meio ambiente, possui relação de identificação com a condição do representado, é legitimada pela finalidade da representação e o seu sentido é de representar discursos e ideias. Já a representação da sociedade civil é autorizada pela experiência que os representantes têm em relação ao tema, legitima-se tanto pelo processo como pela finalidade, e seu sentido é dado pela representação de temas e experiências.

Se pensarmos esses três aspectos da representação, é possível perceber como se pode teorizar a representação de uma maneira diferente. Em primeiro lugar, a representação eleitoral deve significar a abertura de um quadro de relacionamento entre diferentes tipos de soberania (YOUNG, 2000). Nesse sentido a eleição decide uma maneira através da qual corpos representativos se relacionarão com a advocacia e a representação da sociedade civil. Esta relação pode ser mais ou menos complementar, dependendo da proposta política eleita, ainda que no Brasil a relação entre representação eleitoral e não eleitoral tenha sido um dos elementos comuns dos últimos governos. No caso do Brasil, a eleição tem determinado também a maneira como um tipo de representação é capaz de legitimar o outro (AVRTIZER, 2007, p. 458 e 459).

O autor destaca um aspecto importante dessas novas formas de representação: elas não aparecem puras na política. Esse é um dos aspectos mais significativos, pois, quando procuramos compreender o que acontece em espaços de participação, como é o caso dos Conselhos Municipais, devemos considerar 
não somente a forma de autorização dos representantes ali constituídos e questões referentes à legitimação destes espaços, mas todo o jogo político local. É importante identificar se o poder executivo faz um movimento para legitimar as ações dos conselhos, e se membros do poder legislativo estão buscando legitimarse perante seus eleitores através da relação com representantes de determinados temas. Talvez assim, seja possível compreender como as novas formas de representação se sobrepõem em um sistema político de múltiplas soberanias.

O que parece ocorrer nos conselhos, como destacado por Abers e Keck (2008), é um processo de "interação inovadora" entre os diferentes atores, com recursos e demandas diversas, onde, além da aquisição da legitimidade, o que é representado está em constante movimento e deve ser pensado considerando o jogo político local. As autoras defendem que, devido à diversidade envolvida nessa interação, os conselhos são espaços que propiciam a produção de novas práticas para sanar demandas, estas novas práticas se tornam objetos que devem ser mais profundamente estudados.

Lígia Lüchmann e Clara Almeida (2010) em estudo sobre a presença das mulheres nos conselhos municipais de Concórdia (SC) relacionam a significativa presença feminina às inovações criadas por esse fórum tanto no formato de seleção dos representantes quanto nos significados atribuídos a essa representação, em comparação com o campo político partidário e eleitoral.

As autoras apresentam fatores e variáveis da literatura que trata do fenômeno da participação política. Primeiramente, o perfil socioeconômico dos participantes é central. A literatura que sustenta esta perspectiva aponta para a relação entre participação e status socioeconômico, onde "a importante correlação entre educação, renda e ocupação, cuja combinação positiva permite maior propensão, interesse, capacidade e disposição à participação política" (LÜCHMANN e ALMEIDA, 2010, p. 88). Esta correlação é mediada pelos custos da participação: o tempo despendido em contatos, reuniões, etc; o custo emocional (as desilusões pelo não retorno do dispêndio de alta energia e investimento; as hostilidades enfrentadas no mundo da política; as pressões e ansiedades por que passam os indivíduos que participam das tomadas de decisão). Um segundo fator seriam as associações entre o feminino e o espaço doméstico, e o masculino e o espaço da política, ou seja, a divisão do trabalho político (LÜCHMANN e ALMEIDA, 2010, p. 89).

Os dados da pesquisa realizada em conselhos do município de Concórdia, em relação à percentagem de conselheiras (Conselho Municipal de Direitos da Criança e do Adolescente com 71,4\%, Conselho Municipal de Assistência Social com 61,9\% e o Conselho Municipal da Saúde com 43,7\%), evidenciam o predomínio da participação feminina. Em suas palavras: 
A explicação para este fenômeno exige explorar as especificidades que conformam tais instâncias, que se distanciam, de forma significativa, das configurações do sistema político eleitoral e não se enquadram nas concepções assentadas na dicotomia entre participação convencional e não convencional (LÜCHMANN e ALMEIDA, 2010, p. 89).

As autoras (2010) ressaltam duas características centrais da composição dos conselhos - a paridade na representação entre sociedade civil e Estado e a participação por representação de entidades ou organizações da sociedade civil que dificultam o enquadramento destes na distinção entre "participação convencional e não convencional" 5 . Os conselhos combinam elementos dos dois tipos de participação: participação direta em fóruns e participação intermediada por organizações da sociedade civil, desenhando uma nova modalidade de representação, podendo resultar em assembléias com participação de diferentes atores.

Na sequência do trabalho, Lüchmann e Almeida (2010) apresentam os fatores apontados pela literatura que tratam dos obstáculos que o sistema partidário e eleitoral impõe à participação das mulheres na política institucional brasileira, quais sejam: a resistência que as candidaturas femininas enfrentam no interior dos partidos e a reprodução de padrões culturais que atribuem responsabilidades específicas para cada gênero. Para elas, estes fatores sugerem algumas comparações entre a modalidade de escolha que preside o sistema eleitoral e a que preside a escolha dos conselheiros.

$\mathrm{Na}$ competição partidária eleitoral, os candidatos e as candidatas se expõem à sociedade e, portanto, ao crivo dos valores culturais mais amplo e profundamente partilhados, cujas mudanças dependem de um tempo mais longo, e nem sempre seguem um ritmo contínuo e progressivo. Como vivemos numa sociedade que ainda atribui ao gênero feminino a responsabilidade de cuidar do ambiente doméstico e, ao masculino, do mundo público, esses últimos têm, evidentemente, mais chances de obter sucesso no crivo eleitoral. Ou seja, as chances das mulheres obterem audiência receptiva às suas candidaturas por parte do eleitorado, por mais que não defendam bandeiras feministas, são mais reduzidas quando competem ao lado de homens diante de toda a sociedade (LÜCHMANN e ALMEIDA, 2010, p. 90).

E para fazer o contraponto a esta situação, as autoras argumentam que nos conselhos a escolha dos representantes é mediada por organizações da sociedade

\footnotetext{
${ }^{5}$ Participação convencional - atividades relacionadas aos mecanismos governamentais de tomada de decisão, entre elas: votar em eleições, plebiscitos e referendos, participar de campanhas e partidos políticos, atuar como representante político. Participação não convencional - conjunto de iniciativas e de atividades desenvolvidas por fora dos canais formais e da arena institucional, como por exemplo: participar de manifestações, protestos, movimentos sociais e ONGs.
} 
civil e, em várias circunstâncias, resulta de fóruns públicos das diversas áreas de políticas. Sendo assim, o que está em jogo na escolha dos representantes, não são os indivíduos em si, mas as ideias e princípios. Sugerem que a significativa presença de mulheres nos conselhos está relacionada à forma de escolha das representantes, pois esta forma de escolha, sendo intermediada pela sociedade civil, funciona como um filtro que intercede sobre as discriminações de gênero, "a experiência dos conselhos mostra que o vínculo entre 'sociedade civil' e 'representação' é mais favorável à inclusão política das mulheres do que o vínculo entre 'indivíduo' e 'representação"” (LÜCHMANN e ALMEIDA, 2010, p. 91).

Outro aspecto analisado pelas autoras é a maior concentração de mulheres nos conselhos que tratam de temas sociais. De acordo com a literatura apresentada, este predomínio de mulheres nos conselhos das áreas sociais deve-se menos a sua suposta inclinação de "cuidar dos outros" e mais porque se trata do "nicho disponível para elas no campo político" (LÜCHMANN e ALMEIDA, 2010, p. 92), como anteriormente destacado por Luís Felipe Miguel (2000).

Os conselhos municipais das mulheres possuem algumas particularidades. A mais óbvia e importante diz respeito ao recorte de gênero da representação. São conselhos temáticos que representam um grupo que historicamente tem sido minoritário em termos de presença nos fóruns decisórios. Sua fundação depende da mobilização das mulheres da comunidade que tem de pressionar o poder público. Em geral não possuem verbas, recursos humanos e infraestrutura para o funcionamento, por isso são em número limitado: a Secretaria de Políticas para as Mulheres informa 449 conselhos em funcionamento, distribuídos pelo país. Talvez os conselhos que tratam dos direitos da mulher se constituam nos únicos locais onde as mulheres possuam a totalidade das cadeiras, o que não necessariamente corresponde à inexistência de conflitos, de interesses diversos, até mesmo divergentes. Se nos conselhos ocorre uma "interação inovadora" entre atores diversos, propiciando novas práticas para sanar demandas é fundamental verificar quem são os atores e como se desenvolvem as novas práticas, para isso são apresentados dados que compõem o perfil socioeconômico; o perfil político e associativo e o perfil de atuação nos conselhos.

Além desse objetivo geral, algumas questões específicas sobre a atuação feminina nos conselhos serão abordadas: neste espaço, onde há $100 \%$ de representação feminina, é possível perceber o vínculo entre sociedade civil e representação como mais favorável à inclusão política das mulheres do que o vínculo entre indivíduo e representação, como ocorre no campo político partidário e eleitoral? Como constituem legitimidade para a seleção? Por fim, qual a relação de tais conselheiras com o campo político partidário e eleitoral?

Estas questões servirão de base para pensar os dados coletados nos Conselhos dos Direitos da Mulher dos municípios de Pelotas e Santa Cruz do Sul. 


\section{Os Conselhos dos Direitos da Mulher dos municípios de Pelotas e Santa Cruz do Sul (RS)}

Cabe destacar que os dois municípios em discussão, Pelotas e Santa Cruz do Sul, são muito distintos. O primeiro situa-se ao sul do estado, região conhecida como metade sul, considerada a região mais pobre do estado do Rio Grande do Sul. Conforme o censo de 2010 do IBGE, o município de Pelotas possui 328.275 habitantes (53\% mulheres e $47 \%$ homens), é polo regional por ser a maior cidade e concentrar o maior número de serviços. Sua história é marcada pela produção de charque no século XIX com utilização de trabalho escravo, modelo de produção que deixou como herança uma elite que concentra grande parte da riqueza frente a uma massa de cidadãos empobrecidos, o que fica demonstrado pelo PIB per capita/2008 que é de $\mathrm{R} \$ 10.386,48$.

Já o município de Santa Cruz do Sul localiza-se na região nordeste do estado, constituiu-se a partir da colonização alemã e é marcado fortemente pela industrialização, com destaque para a indústria fumageira. Sua população é de 118.374 habitantes (52\% mulheres e 48\% homens), seu PIB per capita/2008 é de $\mathrm{R} \$ 27.128,70$. Apesar das destacadas diferenças, o PIB dos dois municípios é similar: Pelotas soma R\$ 3.564.296, enquanto Santa Cruz do Sul soma $\mathrm{R} \$ 3.287 .130$.

Nos dois municípios, os conselhos da mulher foram criados na década de 1990 pelos respectivos executivos municipais através de leis específicas. Alguns dados são comuns aos dois: todas as conselheiras são mulheres, não possuem destinação de verba, dependendo para seu funcionamento da "boa vontade" da prefeitura, o que resulta na ausência de recursos financeiros e humanos para o pleno funcionamento ${ }^{6}$; as reuniões são mensais e acontecem em dias úteis, no horário comercial e na área central das cidades, o que exige disponibilidade de tempo e de deslocamento das conselheiras.

O Conselho Municipal da Mulher de Pelotas (CMM) foi fundando em 09 de julho de 1992 (Lei $\mathrm{n}^{\text {o }}$ 3.552); sua criação resulta da luta de mulheres organizadas na cidade, principalmente o Movimento Contra a Violência à Mulher que une mulheres oriundas da Igreja Católica, do Partido dos Trabalhadores (PT), de sindicatos de professores, bem como de mulheres autônomas ${ }^{7}$. Na gestão 2008/2010 o conselho estava composto de 15 entidades, sendo que quatro representavam o poder público e 11 representavam a sociedade civil ${ }^{8}$. Dentre as

\footnotetext{
${ }^{6}$ Pelotas disponibiliza um prédio para o funcionamento dos conselhos, a Casa dos Conselhos, porém o Conselho da Mulher não dispõe de sala permanente, apenas de espaço para realização das reuniões mensais. Em Santa Cruz do Sul não há sequer um local específico para as reuniões, elas ocorrem uma vez por mês no plenário da Câmara de Vereadores (SCHULZ, 2010).

${ }^{7}$ Conforme Santos, entre maio de 1989 e abril de 1990, ocorreram três assassinatos de mulheres no município de Pelotas, gerando significativa mobilização das mulheres (SANTOS, 2007).

${ }^{8}$ A lei de fundação do Conselho da Mulher de Pelotas estipula um número total de 15 conselheiras com igual número de suplentes, sendo nove representantes da comunidade e seis representantes governamentais. A lei define as entidades da comunidade. Porém, na gestão analisada há um
} 
11 entidades da sociedade civil, apenas três tratavam especificamente de questões ligadas às mulheres 9 .

O caso do Conselho dos Direitos da Mulher de Santa Cruz do Sul (CMDM) exemplifica a importância da mobilização das mulheres no interior do estado. O CMDM foi criado em 27 de outubro 1994 (Lei no 2.664), resultado da mobilização feminina, e desativado pelo poder executivo municipal em outubro de 1996. A pressão do movimento de mulheres levou a sua reativação em março de 2001, sob nova lei $\left(n^{\circ} 3.686\right)^{10}$. O conselho é paritário, com dez representantes do poder público e dez representantes da sociedade civil, totalizando 20 conselheiras titulares e mais 20 suplentes. Interessante destacar que, durante a gestão 2008/2010, nenhuma das dez entidades representantes da sociedade civil era especificamente de movimento ou organização de mulheres ou feminista ${ }^{11}$.

Nos dois conselhos foram aplicados questionários com as conselheiras, em ambos os casos nem todas as conselheiras titulares responderam. No Conselho Municipal da Mulher de Santa Cruz do Sul foram contatadas 20 conselheiras titulares, sendo que 19 aceitaram o convite para participar da pesquisa (dez representantes da sociedade civil e nove do poder público), 12 conselheiras suplentes desejaram participar (oito da sociedade civil e quatro do poder público), totalizando 31 conselheiras que responderam aos questionamentos. Em Pelotas os obstáculos foram maiores. Como destacado, a lei de fundação do conselho estipula em 15 o número de conselheiras, sendo nove representantes da sociedade

desencontro com a lei: algumas entidades deixaram de existir e verificou-se a presença maior das representantes da sociedade civil. As entidades presentes no Conselho Municipal da Mulher de Pelotas no momento da pesquisa são: Governamentais - Secretarias Municipais de Educação; de Projetos Especiais; de Assistência Social e de Cidadania e Qualidade Ambiental; NãoGovernamentais - ABMCJ (Associação Brasileira de Mulheres da Carreira Jurídica); Conselho Regional de Psicologia; OSC Gesto (Grupo pela Educação, Saúde e Cidadania); ONG Vale a Vida; Associação dos Diabéticos de Pelotas; Teia Ecológica (Cooperativa de consumo, trabalho e produção); MMTU (Movimento de Mulheres Trabalhadoras Urbanas); GAMP (Grupo Autônomo de Mulheres de Pelotas); Sindicato dos Trabalhadores das Indústrias da Alimentação; Sindicato dos Empregados em Empresas de Asseio e Conservação em Pelotas; Igreja Nossa Senhora da Luz. ${ }^{9}$ As demais entidades eram diferentes direitos e produção de renda, corporativas e uma ligada a igreja católica (SCHULZ, 2010).

${ }^{10}$ A representação titular do conselho na gestão 2008/2010 estava assim dividida: Governamentais - Gabinete do Prefeito; INSS (Instituto Nacional de Seguridade Social); Brigada Militar; CORSAN; Secretaria da Agricultura; SMEC (Secretaria da Educação e Cultura); Secretaria do Turismo; Secretaria do Desenvolvimento Social; Secretaria da Saúde; 6a CREA; NãoGovernamentais - UNISC (Universidade de Santa Cruz do Sul); OAB (Organização de Advogados do Brasil); CPERGS (Sindicato Professores RS); SINTAE (Sindicato dos Trabalhadores em Administração Escolar); Associação Diocesana de Santa Cruz do Sul; Sindicato dos Bancários; ACICOM - Associação Cultural de Integração Comunitária; UNIFORTE Cooperativa de Trabalhadores do Bom Jesus; Sindicato dos Trabalhadores Rurais; DCE/UNISC.

${ }^{11}$ Apenas a UNIFORTE tem presença marcantemente feminina. As demais não são direcionadas especificamente às mulheres: a ACICOM é uma associação comunitária, uma das vagas está destinada à igreja, duas estão destinadas à Universidade de Santa Cruz do Sul (UNISC) e cinco são corporativas (SCHULZ, 2010). 
civil e seis do poder público. Porém, a realidade da pesquisa mostrou um quadro bastante diferente. O Conselho da Mulher de Pelotas estava vivendo um renascimento, após um período de esvaziamento que beirou a desativação. Muitas das conselheiras que participavam das reuniões mensais durante a pesquisa não eram titulares, mas mantinham constância de presença. Optamos por aplicar os questionários com aquelas mulheres que estavam participando da reativação, assim totalizamos 15 entrevistas, sendo 11 de representantes da sociedade civil e quatro de representantes do poder público.

Feitas as ressalvas, passamos aos dados. Entre as conselheiras que aceitaram participar da pesquisa é bem mais alto o número de representantes da sociedade civil. Em Pelotas, 73,3\% das conselheiras entrevistadas vem da sociedade civil. Já em Santa Cruz, esse índice cai para 58\%, porém ainda é menor a concordância das representantes indicadas pelo poder público.

Os dados resultantes da aplicação do questionário com as conselheiras dos dois conselhos são tratados comparativamente, buscando elaborar o perfil das conselheiras, para compreender quem são as mulheres que representam as demandas por direitos da mulher e quais as trajetórias que lhes permitem legitimidade para representar todas as demais mulheres da comunidade. Assim, o perfil é composto por dados: socioeconômicos, políticos, associativos e de atuação no conselho.

\section{- Perfil socioeconômico das conselheiras}

O perfil socioeconômico é formado pelas variáveis: idade, estado civil, maternidade, renda, escolaridade, exercício de atividade remunerada (em caso positivo, no setor público ou privado). No que se refere à faixa etária das conselheiras, os dois conselhos oferecem informações similares: a maioria das representantes apresenta idade igual ou superior a 46 anos. Em Pelotas são 12 representantes nesta faixa de idade, equivalendo a $80 \%$. No Conselho de Santa Cruz este índice diminui para 54\% (17 conselheiras), revelando a presença de mulheres mais jovens (23\%, o que são sete conselheiras, que possuem entre $20 \mathrm{e}$ 34 anos, e em igual percentual possuem entre 35 e 45 anos).

Sobre o estado civil das conselheiras, nos dois Conselhos predomina a presença de mulheres casadas, também com índices similares, sendo 53,3\% em Pelotas e 52\% em Santa Cruz do Sul. É significativa a presença de mulheres divorciadas, índices semelhantes nos dois conselhos (33\% em Pelotas e $29 \%$ em Santa Cruz do Sul). Em ambos a maioria das conselheiras possui filhos, sendo 86,7\% das conselheiras de Pelotas e 74\% de Santa Cruz do Sul. 
Tabela 1 - Renda e Escolarização das Conselheiras

\begin{tabular}{c|c|c|c|c}
\hline \multirow{2}{*}{ Faixa de renda: } & \multicolumn{2}{|c|}{ Pelotas } & \multicolumn{2}{c}{ Santa Cruz do Sul } \\
\cline { 2 - 5 } & $\mathbf{N}^{\mathbf{0}}$ & $\mathbf{\%}$ & $\mathbf{N}^{\mathbf{0}}$ & $\mathbf{\%}$ \\
\hline Até 2 SM & 05 & 33,3 & 06 & 19,3 \\
\hline Entre 2 a 5 SM & 06 & 40 & 09 & 45,2 \\
\hline Entre 5 a 10 SM & 03 & 20 & 02 & 29 \\
\hline Mais de 10 SM & - & - & - & 6,5 \\
\hline Não informou & 01 & 6,7 & 02 & - \\
\hline Grau de escolaridade: & \multicolumn{4}{|c}{6,5} \\
\hline Fundamental incompleto & 04 & 26,6 & 01 & 3,3 \\
\hline Fundamental completo & 01 & 6,7 & - & - \\
\hline Médio incompleto & 01 & 6,7 & 06 & 19,3 \\
\hline Médio completo & 01 & 6,7 & 05 & 16,1 \\
\hline Superior incompleto & - & - & 11 & 35,5 \\
\hline Superior completo & 05 & 33,3 & 06 & 19,3 \\
\hline Pós - Graduação & 03 & 20 & 31 & 100 \\
\hline Total & 15 & 100 & &
\end{tabular}

Fonte: Elaboração própria.

Quanto à variável renda, a média está entre dois e cinco salários mínimos, sendo $40 \%$ no Conselho de Pelotas e 45,2\% no Conselho de Santa Cruz do Sul. Cabe destacar que, em relação aos demais percentuais ligados à variável, existe diferenciação: enquanto em Santa Cruz há 35,5\% (11 representantes) com ganhos acima de cinco salários mínimos, em Pelotas ocorre o inverso: 33\% (cinco representantes) afirmam ter renda até dois salários mínimos. Estes dados parecem ir ao encontro das realidades socioeconômicas dos municípios destacadas anteriormente.

O grau de escolaridade das conselheiras pode contribuir para clarear a informação da diferença de renda. Novamente encontramos semelhanças nos percentuais médios quanto à escolaridade. Os dados mostram altos índices de escolarização, onde a maioria das conselheiras já havia concluído um curso de graduação: em Pelotas, 53,3\% das conselheiras tem ensino superior e, em Santa Cruz do Sul, esse índice fica em 54,8\%. Relevante ainda é o índice de quase $20 \%$ de representantes que possuem pós-graduação ${ }^{12}$.

No caso de Santa Cruz do Sul há um significativo percentual de representantes com ensino superior incompleto $(16,1 \%)$. Se somarmos os três índices (superior incompleto, superior completo e pós-graduação), $80 \%$ das

12 Os dois municípios possuem universidades, o que sem dúvida contribui para a alta escolarização. Em Pelotas há universidade pública (UFPel) e privada (UCPel). Em Santa Cruz há apenas uma universidade privada (UNISC). 
conselheiras possuem alta escolarização ${ }^{13}$.

Os dados de Pelotas revelam disparidade de escolarização: 33,3\% das conselheiras possuem apenas o fundamental completo, enquanto 53,3\% têm ensino superior completo. Se cruzarmos os dados de renda e escolaridade, verificamos que os índices de baixa escolaridade $(33,3 \%)$ são similares aos de baixa renda $(33 \%)$.

Constatou-se na pesquisa significativa distinção em relação ao exercício de atividade remunerada das conselheiras de Pelotas e de Santa Cruz do Sul. No Conselho de Pelotas, pouco mais da metade das conselheiras $(53,3 \%)$ realiza algum tipo de atividade remunerada. As sete conselheiras restantes são aposentadas, o que evidencia a disponibilidade de tempo para a participação nas atividades do conselho. Já em Santa Cruz do Sul, a maioria das conselheiras $(81 \%)$ atua de forma remunerada.

As conselheiras que responderam positivamente a questão sobre o exercício de atividade remunerada foram inquiridas sobre qual o setor da atividade. No Conselho da Mulher de Pelotas o exercício de atividade remunerada esta dividido igualmente entre público e privado. Já no Conselho de Santa Cruz o destaque está na elevada presença de trabalhadoras do setor público (72\%).

É possível constatar que apesar da distinção dos municípios em termos de população, atividade produtiva e renda, há similaridades em termos do perfil socioeconômico das mulheres que atuam nestes fóruns: mulheres adultas, casadas e com filhos, que exercem ou exerceram atividade remunerada, principalmente no setor público, com alta escolaridade, porém com renda baixa ao considerar o grau de escolarização.

\section{- Perfil político e associativo das conselheiras}

O perfil político e associativo resulta das seguintes variáveis: participação em outros conselhos, participação em movimentos sociais, associações ou ONGs, relação ou participação em partidos políticos, candidatura a cargos públicos e atuação como representantes em cargos, fóruns ou instituições. A partir destas variáveis, a proposta é pensar a trajetória das conselheiras, pois esta pode sugerir informações sobre a aquisição de capital ou de legitimidade para a indicação, o convite ou a seleção como representante.

${ }^{13}$ Este alto índice não é novidade no Conselho de Santa Cruz do Sul, pesquisa realizada por Grunevald (2009) com as conselheiras da gestão 2007/2009 mostra que dentre as 18 conselheiras entrevistadas, 16 possuíam ensino superior, e dentre estas, sete conselheiras tinham pós-graduação. 
Tabela 2 - Esfera Associativa: Participação em outros Conselhos e Filiação Partidária

\begin{tabular}{|c|c|c|c|c|}
\hline \multirow{2}{*}{$\begin{array}{l}\text { Atualmente você participa de algum } \\
\text { movimento social, sindicato, } \\
\text { associação, ONG? }\end{array}$} & \multicolumn{2}{|c|}{ Pelotas } & \multicolumn{2}{|c|}{ Santa Cruz do Sul } \\
\hline & $\mathbf{N}^{\mathbf{o}}$ & $\%$ & $\mathbf{N}^{\mathbf{o}}$ & $\%$ \\
\hline Sim & 11 & 73,3 & 16 & 51,6 \\
\hline Não & 04 & 26,7 & 15 & 48,4 \\
\hline \multicolumn{5}{|l|}{$\begin{array}{l}\text { Você participa de mais de um } \\
\text { Conselho? }\end{array}$} \\
\hline Sim & 04 & 26,7 & 10 & 32 \\
\hline Não & 11 & 73,3 & 21 & 68 \\
\hline \multicolumn{5}{|l|}{$\begin{array}{l}\text { Em relação aos partidos políticos, } \\
\text { você é: }\end{array}$} \\
\hline Indiferente & 07 & 46,7 & 06 & 19,4 \\
\hline Simpatizante & 05 & 33,3 & 08 & 25,8 \\
\hline Apartidária & - & - & 01 & 3,2 \\
\hline Filiada & 03 & 20 & 16 & 51,6 \\
\hline Total & 15 & 100 & 31 & 100 \\
\hline
\end{tabular}

Fonte: Elaboração própria.

A maioria das conselheiras declara participar de entidade ou organização social. Em Pelotas, 73,3\% respondem afirmativamente e, em Santa Cruz do Sul, o índice é de $51,6 \%$.

Os altos índices de participação em entidades ou organizações sociais, particularmente dos membros do Conselho de Pelotas, não parecem projetar atuação em outros conselhos municipais, pois menos de $30 \%$ responderam afirmativamente à questão. Os resultados do questionamento sobre a posição em relação aos partidos políticos são interessantes, pois apresentam diferença significativa. O índice mais próximo é de simpatizantes.

Em cada um dos conselhos há um destaque: no caso de Santa Cruz trata-se do alto índice de filiadas, pouco acima de 50\%, e no caso de Pelotas do índice de indiferentes, que se aproxima dos 50\%. No conselho de Santa Cruz do Sul as 16 conselheiras filiadas se dividem nos seguintes partidos políticos: nove do PT; três do PSB; duas do PTB; uma do PP; uma não respondeu. Doze conselheiras, que equivalem a $75 \%$ das filiadas, estão vinculadas a partidos do campo da esquerda. Em sua maioria, as simpatizantes também se ligam ao campo da esquerda (cinco entre oito conselheiras). É importante lembrar que no momento da pesquisa a Prefeitura do município estava nas mãos de uma coligação composta por PTB e PT.

No caso do conselho de Pelotas apenas $20 \%$ são filiadas. Sendo que das quatro conselheiras que representam o governo: uma afirma ser indiferente e as outras três são simpatizantes do Partido Progressista (PP), partido que domina o 
Executivo Municipal do município no momento da pesquisa. Dentre as 11 conselheiras não-governamentais, seis são indiferentes aos partidos políticos; duas são simpatizantes (PT) e três são filiadas (PT, PCdoB e PSDB). O fato do poder público indicar as representantes ao conselho não parece refletir sobre a preferência partidária das conselheiras, mesmo quando são cargos de confiança como acontece com três das conselheiras governamentais.

No conselho de Santa Cruz os dados diferem. Dentre as 16 conselheiras filiadas, sete representam o poder público, todas filiadas a partidos da base do governo municipal (PT, PTB e PSB). Por fim, é interessante destacar que a maioria das filiadas são conselheiras representantes da sociedade civil.

Índices interessantes resultam do questionamento sobre a candidatura a cargo público. Como vimos, Pelotas apresenta baixo índice de filiação partidária (20\%) e nenhuma conselheira que tenha sido candidata a cargo público. Santa Cruz, por outro lado, apresenta índice relevante de conselheiras filiadas a partidos políticos, porém $90,3 \%$ nunca se candidataram a cargo público. O campo político partidário eleitoral parece manter-se fechado a estas mulheres que possuem algum capital que permite sua seleção para representantes neste fórum.

A próxima questão a ser apresentada pode esclarecer um pouco onde as representantes adquirem legitimidade para a presença no conselho. A pergunta "você já foi representante em algum cargo, fórum ou instituição?" obteve os seguintes resultados: 33,3\% das conselheiras de Pelotas já foram representantes em Conferências de saúde, da mulher ou da educação. Em Santa Cruz do Sul, o índice é um pouco mais baixo, 25,8\% das conselheiras já foram representantes nos seguintes cargos, fóruns ou instituições: sindicatos, orçamento participativo, conferências, órgãos públicos e igreja.

O perfil associativo das conselheiras mostra mulheres atuantes na sociedade, porém esta atuação não se reflete em participação em mais de um conselho. Em termos políticos não foi possível construir um claro perfil, dada a discrepância dos dados. Porém, do cruzamento de variáveis emerge algumas considerações: no Conselho de Santa Cruz há uma analogia entre os índices de participação em entidades e organizações sociais (55\%) com os índices de filiação política (51,6\%); em Pelotas ocorre o inverso, é admirável a diferença entre os índices de participação em entidades e organizações $(73,3 \%)$ e os índices de filiação partidária (20\%).

Ainda caracterizando as mulheres que compõem os conselhos algumas considerações emergem do chamado perfil associativo e político das conselheiras. Os dados demonstram que em sua maioria são mulheres atuantes em suas comunidades o que lhes dá legitimidade para representarem as demais. Porém, a atuação está desvinculada do campo político partidário e eleitoral. Embora atores sociais importantes em suas comunidades, tais mulheres não são cooptadas pelos partidos políticos para serem candidatas a cargos públicos eletivos (mesmo aquelas filiadas a partidos), dado interessante se considerarmos as dificuldades 
enfrentadas pelos partidos para cumprirem a lei de cotas que estipula um percentual mínimo e máximo por gênero nas listas partidárias. Sem dúvida, as informações contidas na resposta não fecham a questão, pois além dos limites impostos pelos partidos políticos à entrada das mulheres na política, é necessário considerar a hipótese de que elas podem não ter interesse em construir uma carreira política partidária e eleitoral ${ }^{14}$.

\section{- Perfil da atuação das representantes nos Conselhos}

As variáveis que compõem o perfil de atuação das conselheiras são: número de mandatos, participação nas plenárias, diferenças de atuação entre representantes do poder público e da sociedade civil, influência do partido governante nas decisões, capacidade do conselho de cumprir suas funções e temas mais presentes. Nos dois conselhos investigados a maioria das conselheiras respondeu que atua apenas no Conselho da Mulher. É semelhante para os dois conselhos - em torno de 50\% - o índice de conselheiras que atuam a mais de um mandato. Cabe destacar que para muitas delas trata-se do primeiro mandato de conselheira titular, sendo 33,3\% em Pelotas e 20\% em Santa Cruz do Sul.

Ao serem questionadas sobre o nível de participação durante as plenárias dos conselhos as respostas dividem-se, principalmente, entre "ativa em parte" e "muito ativa" 15 . Se somarmos os índices de "ativa em parte" e "muito ativa" para os dois fóruns temos resultados respeitáveis: no conselho de Santa Cruz o índice fica em 81\%; em Pelotas este índice diminuiu um pouco, mais ainda é muito significativo: $73,3 \%$. Os dados demonstram que as conselheiras têm uma percepção muito positiva de sua atuação.

A expectativa no momento da pesquisa era encontrar divergências ou distinções na atuação das conselheiras, particularmente ligadas ao local que ocupam no conselho em função de representarem poder público ou sociedade civil. Porém, os dados surpreendem, pois a maioria das conselheiras acredita que estas distinções não existem (66,7\% em Pelotas e 54,8\% em Santa Cruz do Sul).

\footnotetext{
${ }^{14}$ Os estudos sobre a sub-representação feminina no legislativo brasileiro apontam para problemas relacionados ao sistema eleitoral e partidário, mas também as questões culturais como limitadoras da presença das mulheres (ARAÚJO, 2001e 2009; MIGUEL, 2000; PINTO, 2010).

${ }_{15}$ Pelotas: Pouco ativa 13,3\%; Ativa em parte 40\%; Muito ativa 33,3\%; Nenhuma 6,7\% e Não informou 6,7\%. Santa Cruz do Sul: Pouco ativa 6\%; Ativa em parte 39\%; Muito ativa 42\%; Nenhuma 3\% e Ainda não participou $10 \%$.
} 
Tabela 3 - Influência político partidária nas decisões do Conselho e Reação do Executivo às propostas do Conselho

\begin{tabular}{c|c|c|c|c}
\hline \multirow{2}{*}{$\begin{array}{c}\text { Há influência político partidária nas decisões } \\
\text { Conselho? }\end{array}$} & \multicolumn{2}{|c|}{ Pelotas } & \multicolumn{2}{c}{ Santa Cruz } \\
\cline { 2 - 5 } Sim & 02 & 13,3 & 04 & 12,9 \\
\hline Não & 12 & 80 & 24 & 77,4 \\
\hline Não sabe/Não respondeu & 01 & 6,7 & 03 & 9,7 \\
\hline $\begin{array}{c}\text { Como o Executivo se relaciona com as } \\
\text { propostas de políticas defendidas pelo } \\
\text { Conselho? }\end{array}$ & & & & \\
\hline Sempre executa & & & & \\
\hline Neleciona algumas para executar & 06 & 40 & 23 & 74,2 \\
\hline Não executa nunca & - & - & - & - \\
\hline Só executa se a proposta partiu da Prefeitura & - & - & 01 & 3,2 \\
\hline Não sabe/Não respondeu & 03 & 20 & 02 & 6,4 \\
\hline Total & 15 & 100 & 31 & 100 \\
\hline
\end{tabular}

Fonte: Elaboração própria.

A Tabela 3 apresenta dados interessantes. Nos dois conselhos são altos os índices de respostas negativas à questão que trata da influência político partidária nas decisões do Conselho.

Interessante também foram os resultados da percepção das conselheiras em relação à recepção por parte do Executivo das propostas defendidas pelo Conselho. Nenhuma das conselheiras escolhe a alternativa "não executa nunca". No caso de Santa Cruz o destaque é para a opção "seleciona algumas para executar". Já em Pelotas o que chama atenção é o índice de $40 \%$ que afirma que o Executivo "sempre executa" as políticas defendidas pelo Conselho.

As conselheiras foram questionadas ainda sobre os temas relacionados à condição da mulher (as demandas) mais presentes no Conselho. Os quatro temas mais citados coincidem, porém não na mesma ordem. No conselho de Santa Cruz do Sul a ordem de citação foi: violência, pobreza, saúde, trabalho. No conselho de Pelotas: violência, saúde, trabalho e pobreza. A violência contra a mulher é o tema mais presente nas falas das conselheiras dos dois conselhos. Quanto ao tema trabalho, há uma subdivisão: em Pelotas o tema é geração de trabalho e renda e em Santa Cruz é discriminação no trabalho.

A última questão a ser apresentada trata da credibilidade das conselheiras no Conselho onde atuam. Nos dois casos passa de $90 \%$ a alternativa que responde positivamente a pergunta "Em sua opinião, o Conselho cumpre as funções para as quais foi criado?” (93,3\% em Pelotas e 93,5\% em Santa Cruz do Sul).

Ao serem questionadas sobre a capacidade de o Conselho cumprir suas 
funções, praticamente todas as conselheiras dos dois municípios afirmam que o Conselho da Mulher de seu município cumpre as funções para as quais foi criado.

As últimas variáveis apresentadas possibilitam algumas considerações em termos do que denominamos de perfil de atuação das representantes nos Conselhos: a grande maioria das conselheiras se considera atuante; a quase totalidade avalia que o Conselho cumpre suas funções que são, conforme as leis de fundação, discutir e deliberar políticas públicas locais para as mulheres; há uma percepção de inexistência de significativas diferenças de atuação entre representantes do poder público e da sociedade civil; creem na autonomia dos conselhos frente aos respectivos Executivos Municipais, por fim, há afinidade de temas nos Conselhos. Todos estes fatores conjuntamente sugerem a atuação focada na luta por direitos da mulher, onde diferenças ou divergências, que sem dúvida estão presentes, não parecem ser suficientes para minar uma identidade comum ou uma política de ideias.

\section{Considerações}

À guisa de conclusão podemos afirmar que a ampliação dos locais de discussão e deliberação de políticas públicas, como ocorre com os conselhos, tem favorecido a presença das mulheres como representantes. Todavia, as investigações têm gerado a necessidade de repensar a própria noção de representação, principalmente em relação ao formato de seleção e de legitimidade dos conselheiros, bem como na multiplicidade de demandas de políticas públicas. Além disso, é necessária a multiplicação de estudos para compreender se e como estes fóruns possibilitam a inclusão de segmentos historicamente excluídos das decisões políticas.

Os dados coletados nos Conselhos da Mulher de municípios com diferenças significativas apontam para um perfil semelhante. Em termos socioeconômicos: as conselheiras são mulheres adultas, casadas e com filhos, que exercem ou exerceram atividade remunerada principalmente no setor público. No entanto, possuem renda que não condiz com a alta escolaridade. Estes dados coincidem fortemente com os perfis das representantes femininas que atuam nos legislativos do país, ou seja, o perfil das mulheres que atuam neste fórum é similar àquelas que passam pelo crivo partidário e eleitoral para se tornarem representantes nos parlamentos.

Em relação à atuação das representantes nos conselhos os dados revelam, em termos de perfil, que as conselheiras se percebem como atuantes e avaliam muito positivamente sua atuação, pois a quase totalidade das representantes afirma que os conselhos desempenham as funções para as quais foram fundados. Os dados ainda permitem concluir que as conselheiras enxergam os conselhos como autônomos e as conselheiras como um grupo que atua de forma conjunta, independente da origem da representação.

Ao retomar os questionamentos sobre a relação das conselheiras com o 
campo político partidário e eleitoral e sobre a legitimidade da seleção das representantes, os dados presentes no perfil associativo e político permitem considerações interessantes. Mostram que as conselheiras que participaram da pesquisa são atuantes na comunidade, porém esta atuação não se reflete na construção de uma carreira política tradicional através da entrada no campo político eleitoral, mesmo aquelas que estão filiadas a partidos. A relação com os partidos políticos apontou talvez a maior diferença comparativamente, contudo descortinou dados interessantes: no conselho de Santa Cruz há uma analogia entre os índices de participação em entidades e organizações sociais $(55 \%)$ com os índices de filiação partidária (51,6\%); em Pelotas ocorre o inverso, é admirável a diferença entre os índices de participação em entidades e organizações $(73,3 \%)$ e os índices de filiação partidária (20\%).

As conselheiras se assimilam ao perfil tradicional das vereadoras e das deputadas, pois são mulheres adultas, casadas, com filhos, boa renda e alta escolarização, talvez a grande diferença esteja na ausência da herança política como fator relevante na construção de capital ou legitimidade para a seleção, a legitimidade das conselheiras parece estar muito mais fortemente centrada em sua atuação na comunidade, principalmente, em organizações da sociedade civil.

Sem dúvida, os dados empíricos não se mostram suficientes para generalizações, mas foi possível perceber o vínculo entre sociedade civil e representação como mais favorável à inclusão política das mulheres nos espaços decisórios do que o vínculo entre indivíduo e representação como ocorre no campo político partidário e eleitoral, afinal é a atuação das mulheres nas organizações da sociedade civil que legitima sua presença nos conselhos.

Por fim, os dados parecem apontar para uma relação fecunda entre sociedade civil e poder público, já que as diferenças ou divergências entre as conselheiras parecem dar lugar a uma identidade comum: de mulher. Se internamente a atuação é como grupo ou "bancada" em defesa dos direitos da mulher sugerindo o apagamento das divergências e diferenças, externamente os obstáculos se mostram: as conselheiras denunciam uma série de dificuldades para o pleno funcionamento destes fóruns que se resumem basicamente em falta de recursos humanos e de infraestrutura.

Rosangela Schulz é Professora do Departamento de Sociologia e Política da Universidade Federal de Pelotas (UFPel) e coordenadora do Programa de Pós-Graduação em Ciência Política da UFPel. E-mail: rosangelaschulz@gmail.com

Dieni Oliveira Rodrigues é Mestre em Ciências Sociais pela UFPel. Email: dienirodrigues@gmail.com

Ana Cristina L. Mendes é Mestre em Ciência Política pela UFPel. Email: ana-lubke@hotmail.com 


\section{Referências}

ABERS, Rebecca N.; KECK, Margaret E. Representando a diversidade: Estado, sociedade e "relações fecundas" nos conselhos gestores. Caderno CRH, Salvador, v. 21, n. 52, p. 99-112, jan.-abr. 2008.

ARAÚJO, Clara. Gênero e acesso ao poder legislativo no Brasil: as cotas entre as instituições e a cultura. Revista Brasileira de Ciência Política, Brasília, n. 2, p. 23-59, 2009.

ARAÚJO, Clara. Potencialidades e Limites da Política de Cotas no Brasil. Estudos Feministas, n. 1, p. 231-252, 2001.

AVELAR, Lúcia. Mulheres na elite política brasileira: canais de acesso ao poder. São Paulo: Fundação Konrad Adenauer, 2001.

AVRITZER, Leonardo. Sociedade civil, instituições participativas e representação: da autorização à legitimidade da ação. DADOS - Revista de Ciências Sociais, Rio de Janeiro, v. 50, n. 3, p. 443-464, 2007.

CÂMARA MUNICIPAL DE PELOTAS. Lei $n$. 3552 de 09 de julho de 1992. Cria o Conselho Municipal da Mulher no município de Pelotas.

CÂMARA MUNICIPAL DE SANTA CRUZ DO SUL. Lei $n .2 .664$ de 27 de outubro 1994. Cria o Conselho Municipal dos Direitos da Mulher, o Escritório Municipal de Defesa dos Direitos da Mulher.

CÂMARA MUNICIPAL DE SANTA CRUZ DO SUL. Lei n. 3.686 de 14 de março de 2001. Altera Artigos, Incisos, extingue e acrescenta parágrafos a Lei $\mathrm{n}^{\mathrm{o}} 2.664$.

GROSSI, Mirian, MIGUEL, Sônia. Transformando a diferença: as mulheres na política. Estudos Feministas, Florianópolis, v. 9, n. 1, p. 167-206, 2001.

GRUNEVALD, Débora H. M. O Conselho da mulher de Santa Cruz do Sul: construindo alternativas para demandas femininas. 2009. 178 f. Dissertação de Mestrado (Mestrado em Desenvolvimento Regional) - Programa de PósGraduação em Desenvolvimento Regional, Universidade de Santa Cruz do Sul, Santa Cruz do Sul, 2009.

GURZA LAVALlE, Adrian; HOUTZAGER, Peter; CASTELlO, Graziela. Democracia, Pluralização da Representação e Sociedade Civil. Lua Nova, São Paulo, n. 67, p. 49-103, 2006.

IBGE. Instituto de Brasileiro de Geografia e Estatística. IBGE Cidades. 2008. Disponível em: <www.ibge.gov.br/cidadesat>. Acesso em: 24 out. de 2011.

LÜCHMANN, Lígia H. H.; ALMEIDA, Carla C. R. A representação política das mulheres nos Conselhos Gestores de políticas Públicas. Revista Katál, Florianópolis, v. 13, n. 1, p. 86-94, jan.-jun. 2010.

LÜCHMANN, Lígia H. H. A representação no interior das experiências de participação. Lua Nova, São Paulo, n. 70, p. 139-170, 2007.

MIGUEL, Luis Felipe; QUEIROZ, Cristina M. Diferenças regionais e o êxito relativo de mulheres em eleições municipais no Brasil. Estudos Feministas, Florianópolis, v. 14, n. 2, p. 363-385, 2006. 
MIGUEL, Luis Felipe. Teoria política, feminismo e liberalismo: o caso das cotas de representação. Revista Brasileira de Ciências Sociais, São Paulo, n. 15, v. 44, p. 91-102, 2000.

PINTO, Céli R. J. Feminismo, história e poder. Revista de Sociologia e Política, Curitiba, v. 18, n. 36, p. 15-23, jun. 2010.

PINTO, Céli R. J. Espaços deliberativos e a questão da representação. Revista Brasileira de Ciências Sociais, São Paulo, v. 19, n. 54, p. 98-113, fev. 2004.

PITKIN, Hanna. The concept of representation. Bukeley/London: University of California Press, 1976.

SANTOS, Joaquim L. D. Breve Análise do Feminismo Contemporâneo em Pelotas (1982-2004). 2007. 78 folhas. Monografia (Graduação em História), Universidade Federal de Pelotas, Pelotas, 2007.

SCHULZ, Rosangela M. Mapeando os conselhos municipais dos direitos da mulher: Porto Alegre, Pelotas e Santa Cruz do Sul. In: SCHULZ, Rosangela M. (org.). Ensaios de Sociologia e Política. Pelotas: Editora e Gráfica Universitária - UFPel, 2010. p. 229-268.

Secretaria de Políticas para Mulheres. Lista de conselhos do Brasil. 2012 Disponível em <http://www.spm.gov.br>. Acesso em: 20 mai. 2012.

TÓTORA, Silvana; CHAIA, Vera. Conselhos municipais e a institucionalização da participação: a região Metropolitana de São Paulo. In: SANTOS JR., Orlando A.; RIBEIRO, Luiz César Q.; AZEVEDO, Sérgio (orgs.). Governança democrática e poder local. Rio de Janeiro: Revan/Fase, 2004. p. 193-221.

Texto recebido em 13 de agosto de 2013. Aprovado em 12 de novembro de 2013. 